\section{$\underset{\text { hommes }}{\text { \& migrations }}$}

\section{Hommes \& migrations}

Revue française de référence sur les dynamiques

migratoires

$1330 \mid 2020$

1973, l'année intense

\title{
Sabri Louatah, 404
}

Flammarion, Paris, 2020, 356 pages, $21 €$.

\section{Mustapha Harzoune}

\section{OpenEdition}

1 Journals

\section{Édition électronique}

URL : https://journals.openedition.org/hommesmigrations/11706

DOI : 10.4000/hommesmigrations. 11706

ISSN : 2262-3353

\section{Éditeur}

Musée national de l'histoire de l'immigration

\section{Édition imprimée}

Date de publication : 17 juillet 2020

Pagination : 242-243

ISBN : 978-2-919040-51-3

ISSN : $1142-852 X$

\section{Référence électronique}

Mustapha Harzoune, «Sabri Louatah, 404 », Hommes \& migrations [En ligne], 1330 | 2020, mis en ligne le 01 juillet 2020, consulté le 05 janvier 2023. URL : http://journals.openedition.org/

hommesmigrations/11706; DOI : https://doi.org/10.4000/hommesmigrations.11706 


\section{4}

Sabri Louatah, Paris,

Flammarion, 2020, 356 p., $21 €$.

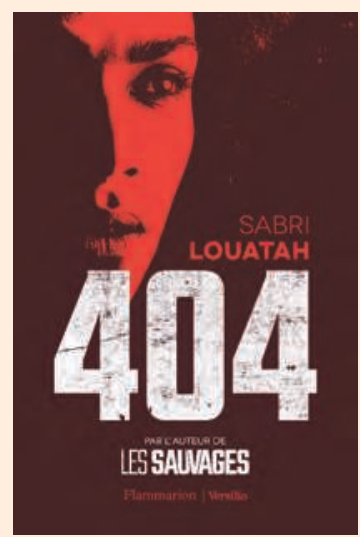

Après Les Sauvages (4 tomes parus entre 2012 et 2016) et sa décevante adaptation en série pour Canal +, après un silence de près de quatre ans, voici donc le roman qui marque le retour de Sabri Louatah. Comme précédemment, celui qui aujourd'hui vit à Philadelphie aux États-Unis écrit selon la technique qui a fait son succès, le procédé moderne et générationnel des séries aux ingrédients indispensables: thématiques dans l'air du temps, rebondissements à répétition, panel de personnages représentatifs, aux intérêts

concurrents voire contraires, profils psychologiques et ressorts émotionnels. Chez Louatah on ouvre un livre comme on allume sa télé. 404 reprend la recette qui a fait le succès des Sauvages. L'indéniable talent est toujours là qui enchaîne les péripéties, met le lecteur sur le gril et laisse filer et s'entrecroiser, telles deux formule 1 sur un circuit rapide, ses deux lignes de force que sont ici les évolutions

technologiques et la citoyenneté plus que racisme. Reste que le rythme de ce roman paraît un peu plus poussif, comme si, ici ou là, la narration toussotait, comme un moteur. Cela tient, sans doute, à la perception (et donc la subjectivité) d'une lecture qui trouve par trop caricatural tel ou tel personnage, ou factices - fabriqués - certaines situations ou événements. Mais l'auteur a tous les droits; et si le lecteur veut sa dosette de réalité, il n'a qu'à ouvrir son quotidien ou écouter les bavardages des chaines d'infos. D'autant plus que, selon Louatah, ce roman-fiction se veut particulièrement à l'écoute du monde, en l'occurrence de la société française et de son incapacité ou de ses difficultés à faire de la place aux siens. À tous les siens.

Quid du «pitch» puisque nous sommes dans un roman-série? Allia, brillantissime et séduisante incarnation de la méritocratie républicaine, invente 404, un logiciel de streaming en direct qu'il est impossible d'enregistrer et donc de rediffuser et de falsifier. «Une sorte de réalité objective», antidote aux «deepfakes», ces «mirages» ou «diableries technologiques» qui se multiplient et polluent la vie démocratique et les élections, empêchent de discerner le vrai du faux, entretiennent incrédulité, déviance, désintérêt. En un mot rongent citoyenneté et lien civique. Nous sommes en 2022, autant dire aujourd'hui.

Ce qui motive Allia (et ceci a été insuffisamment souligné), ce ne sont ni les paillettes de la gloire, ni les bouffissures de la richesse, ni le vertige du pouvoir - ou d'un contre pouvoir (d'autres s'en occupent pour elle...). Non! L'objectif de son 404 (comme le code d'erreur informatique mais aussi comme la bonne vieille 404 bâchées de papa...), c'est de rétablir du lien social, d'apporter à ses contemporains l'outil qui leur permettra de (re) faire société. Si Les Sauvages c'était Balzac chez les Berbérichons (voir H\&M, $n^{\circ}$ 1296), 404 c'est Emma Bovary chez les Franco-Algériens, car le rêve va virer au cauchemar. Bien sûr le terrain est miné, non par l'ennui, mais par le ressentiment et des querelles aussi vieilles que factices. Non content de devoir faire avec ses propres faiblesses, Allia, entre «chaussures Louboutin» et «robe 
kabyle», butera sur les embûches et les manigances qui viennent aussi bien des cercles politiques ou institutionnels, que de cette communauté imaginaire à laquelle on renvoie les Algériens de France - devenus les «musulmans»et leurs rejetons.

"Je suis à plaindre mais non à vendre» dit Emma Bovary. Cela s'applique à merveille à Allia. Et si son échec marque l'incapacité d'une nation bigarrée à faire société, l'idéal, demeure. 404! Il faut redémarrer le système France. C'est dire, malgré les bémols, l'importance du nouveau Louatah. M. H. 